\title{
PANORAMA DA CADEIA PRODUTIVA DA SUINOCULTURA NO ESTADO DE MATO GROSSO
}

\author{
PANORAMA OF THE PRDUCTION CHAIN FROM SWINE FARM IN STATE OF \\ MATO GROSSO
}

\author{
Karine Medeiros Anunciato ${ }^{1}$ \\ Nelson Leitão Paes ${ }^{2}$
}

\begin{abstract}
RESUMO
O presente estudo tem como objetivo geral descrever a cadeia produtiva da suinocultura no estado de Mato Grosso. A metodologia utilizada buscou detalhar a cadeia produtiva da suinocultura através de dados fornecidos da pesquisa de campo da ACRISMAT realizada em 2010, aplicada diretamente com 81 produtores e 09 frigoríficos. Em complemento foram entrevistados representantes de cooperativas deste segmento, no ano de 2014. A ACRISMAT considerou como amostra as microrregiões com maior representatividade no Estado, utilizando a metodologia rapid appraisal para a escolha dos entrevistados nestas microrregiões. Durante a análise da cadeia produtiva, observou-se que o Sistema Intensivo de Suínos Confinados (SISCON), é encontrado em 95\% das granjas do estado, no ano de 2010. Com relação aos tipos de granja dados apontam que $32 \%$ das granjas são do tipo CC, $17 \%$ do tipo UPL e $48 \%$ do tipo UT nas principais regiões produtoras, de suínos do estado de Mato Grosso.
\end{abstract}

Palavras Chaves: Agronegócio, Tipos de Granjas, Sistemas de produção;

\begin{abstract}
This study has the general objective to describe the productive chain of swine in the state of Mato Grosso. The methodology sought to detail the production chain from pig farming through provided data ACRISMAT of field research conducted in 2010, applied directly to 81 producers and 09 refrigerators. In addition we interviewed representatives of cooperatives in this segment in the year 2014. The ACRISMAT considered as a sample of the micro-regions with the largest representation in the state, using rapid appraisal methodology for the selection of respondents in these microregions. During the analysis of the production chain, it was observed that the Intensive

\footnotetext{
${ }^{1}$ Graduada em Economia pela Universidade Federal de Mato Grosso (UFMT). Mestre em Agricultura Tropical pela Universidade Federal de Mato Grosso (UFMT). Doutora em Economia Aplicada pela Universidade Federal de Pernambuco (UFPE). Professora da Universidade Estadual de Mato Grosso (UNEMAT). E-mail: Karine.med@gmail.com

${ }^{2}$ Graduado em Engenharia Mecatrônica pela Universidade de São Paulo (USP). Doutor em Economia pela Universidade de Brasília (Unb). Professor da Universidade Federal de Pernambuco (UFPE). Email:nlpaes@gmail.com
} 
System Confined Pigs (SISCON), is found in $95 \%$ of state farms, in 2010. regarding the types of farm data show that $32 \%$ of farms are CC type, $17 \%$ of the UPL type and $48 \%$ of UT type in the main producing regions of Mato Grosso state pigs.

Keywords: Agribusiness, types of farms, production systems

JEL: O12; L11

\section{Introdução}

Segundo a Associação Brasileira de Produção Animal (ABPA), a produção mundial de carne suína em 2013 foi da ordem de 107.514 mil toneladas, ficando à frente da carne de frango (84.610 mil toneladas) e da carne bovina (57.527 mil toneladas). Os maiores produtores são a China (53.8 mil toneladas), o bloco da União Europeia, considerando 27 países $^{3}$ (22.450 mil toneladas), e os Estados Unidos (10.508 mil toneladas). Juntos são responsáveis por aproximadamente $82 \%$ da produção mundial, sendo que só a China produz 50\% do total mundial (ABPA, 2014).

No Brasil, para que a suinocultura se desenvolvesse, produtores e especialistas investiram na evolução genética na suinocultura nos últimos 20 anos, reduzindo em $31 \%$ a gordura da carne, $10 \%$ do colesterol e $14 \%$ de calorias, tornando a carne suína brasileira mais magra e nutritiva (FRIGG, 2012). Como consequência deste investimento, a produção vem registrando crescimento de 13,15\% no período de 2007 a 2013 (ABPA, 2014).

O rebanho suíno brasileiro que aumentou $13,69 \%$ do ano de 2007 para 2013 . O mercado interno foi responsável pelo consumo de 2.700 mil toneladas em 2013, enquanto 600 mil toneladas foram exportadas representando aumento de 10,6\% em relação ao ano anterior (ABIPECS, 2014).

No estado de Mato Grosso a implantação do programa "Granja de Qualidade", aliado ao clima favorável e disponibilidade de matéria prima para fabricação de ração gerou cenário promissor para a suinocultura, e estimulou a produção de MT, chegando a um plantel de 1,5 milhões de cabeças em 2013, o que corresponde ao $5^{\circ}$ maior

\footnotetext{
${ }^{3}$ Os países da União Europeia: Alemanha, Áustria, Bélgica, Bulgária, Chipre, Dinamarca, Eslováquia, Eslovênia, Espanha, Estônia, Finlândia, França, Grécia, Hungria, Irlanda, Itália, Letônia, Lituânia, Luxemburgo, Malta, Países Baixos (Holanda), Polônia, Portugal, Reino Unido, República Tcheca, Romênia e Suécia
} 
rebanho brasileiro e o maior da região Centro Oeste, gerando 8000 empregos diretos e outros 25 mil indiretos dentro do Estado (ABCS, 2012).

A cadeia produtiva da suinocultura no Brasil já foi descrita e analisada sob diversos aspectos. Dartora, Mores e Woloszyn (1997) descreveram todo sistema produtivo brasileiro de suínos de maneira detalhada, enquanto que a cadeia produtiva do Paraná foi descrita pelo IPARDES (2002). Miele e Waquil (2007a) analisaram as estruturas de contratos entre os elos da cadeia produtiva em Santa Catarina e Santini e Souza Filho (2004a) estudaram as mudanças tecnológicas que estão em curso na cadeia agroindustrial da carne suína no Brasil.

No estado de Mato Grosso, Franco et al (2010) analisaram as estruturas de governança e as transações entre produtores integrados e cooperados, e agroindústria de abate e processamento, da suinocultura e Saraiva (2012) estudou o desempenho competitivo dessa cadeia produtiva. Apesar de existirem muitas pesquisas sobre a cadeia produtiva da suinocultura, ainda faltam análises mais aprofundadas referentes aos custos de produção e tributação no processo produtivo.

Contudo, não foram encontrados estudos referentes ao funcionamento e análise da cadeia produtiva da suinocultura no estado de Mato Grosso. Essas informações podem ajudar a definir ações no sistema agroindustrial da suinocultura, em especial aos agentes formuladores de políticas públicas, considerando que esta é atividade com grande potencial de crescimento. Dessa forma, o estudo é dirigido a pesquisadores, executivos de empresas de agronegócio, diversas esferas governamentais, consultores e interessados em geral em economia do agronegócio.

$\mathrm{O}$ estudo tem como objetivo geral analisar e descrever a cadeia produtiva da suinocultura do estado de MT; na cadeia produtiva da suinocultura no estado de Mato Grosso. E como objetivos específicos tem-se:

- Analisar os segmentos da cadeia produtiva da suinocultura;

- Descrever os sistemas de produção do estado de Mato Grosso;

- Caracterizar as granjas produtoras do estado;

- Analisar o perfil dos produtores;

Em termos metodológicos, utilizou-se dados de pesquisa de campo, realizada em 2010, pela Associação dos Criadores de Suínos de Mato Grosso (ACRISMAT). A pesquisa foi aplicada diretamente aos produtores, cooperativas, frigoríficos e associações pertencentes ao segmento da suinocultura, com o objetivo de conhecer 
melhor a suinocultura de MT, identificando os fatores positivos e negativos enfrentados pelos produtores e empresas.

Os questionários desta pesquisa foram analisados e tabulados de forma a criar um banco de dados pelos autores, observando informações como regiões de estudo, dados das propriedades, custos de produção, tipo de granja, sistema de produção, quantidade de animais por etapa de criação, genética, fase de criação. etc. Este banco de dados produzido foi utilizado nesta tese para identificar a cadeia produtiva da suinocultura. Dada a necessidade de complementar estas informações em 2014, foram realizadas visitas técnicas e novas entrevistas com cooperativas, frigoríficos e especialistas em produção de suínos.

A motivação para este trabalho de pesquisa é informações sobre a cadeia produtiva do estado de Mato Grosso pode fornecer instrumentos para formação de políticas públicas e tomada de decisão dos agentes desta cadeia possibilitando desenvolvimento da atividade.

Na visão de Roche (2013) a maioria dos levantamentos, realizados sobre suinocultura, relacionam fatores como legislação, estrutura de governança, atores sociais envolvidos, entre outros elementos. Contudo, não elucidam com profundidade suas consequências para os produtores e o sistema como um todo. Batalha e Scarpelli (2005) apontam que pesquisas que identifiquem os atributos e características de uma cadeia produtiva são importantes porque evidenciam aos agentes, fatores para tomada de decisão e intervenção nos processos de produção que, interativamente, podem melhorar o desempenho conjunto. Segundo os autores, pesquisas que analisem cadeias produtivas de forma detalhada ainda são raras no Brasil e, quando existentes, são limitadas.

\section{FUNDAMENTAÇÃO TEÓRICA}

A literatura sobre cadeia produtiva da suinocultura é bastante escassa. São poucos os trabalhos nacionais, e até mesmo estrangeiros que se ocuparam de estudar este tema. Nesta seção serão destacadas as principais pesquisas relacionadas e dados deste setor no Brasil e no mundo. Em particular, será apresentada a literatura sobre a cadeia produtiva caracterizando sua composição e os elos de produção desta agroindústria. 


\subsection{Cadeia produtiva}

As especializações das unidades fabris em uma gama mais estreita de produtos, a internacionalização e padronização dos produtos e desenvolvimento da informática permitiram que a produção de uma empresa não mais dependesse da comercialização no mercado na qual se localiza (SCHUTZER; PEREIRA, 1999). Segundo o Instituto Paranaense de Desenvolvimento Econômico e Social (IPARDES) e o Grupo de Estudos e Pesquisas Agroindustriais (GEPAI, 2009), devido a essa descentralização dos processos produtivos, é que se considera a importância de análise sistêmica da produção de bens finais, considerando todas as variáveis internas e externas que influenciam as empresas.

Do distanciamento de centro de consumo e necessidade de uma análise que considere ao mesmo tempo os aspectos específicos dos agentes e suas inter-relações em níveis organizacionais e tecnológicos, surge o conceito de cadeia produtiva. Nesta concepção, segundo Castro, Lima e Cristo (2002, p.8):

[...] uma cadeia produtiva agropecuária seria composta por elos que englobariam as organizações supridoras de insumos básicos para a produção agrícola ou agroindustrial, as fazendas e agroindústrias com seus processos produtivos, as unidades de comercialização atacadista e varejista e os consumidores finais, todo conectados por fluxos de capital, materiais e de informação.

Miele (2007) em seu estudo da cadeia produtiva da suinocultura no Brasil, afirma que no processo de consolidação das organizações desta cadeia nos mercados domésticos a intensificação tecnológica contribuiu no processo de concentração e especialização na produção de animais. O autor concluiu que os agentes buscaram a redução de custos através dos ganhos de escala na suinocultura e na agroindústria, bem como redução dos riscos e aumento da qualidade através da maior coordenação no suprimento de matéria-prima.

Assim em função de novos processos produtivos, do desenvolvimento de novos produtos, busca pela a maximização dos lucros e vantagens competitivas, surge a necessidade da redução dos custos operacionais e melhor gerenciamento dos custos totais da cadeia produtiva. Essas cadeias são dinâmicas e englobam fluxo constante de informações, produtos e recursos financeiros entre diferentes elos (CORREA; SACOMANO NETO; PADOVESE, 2006). 
Segundo Melz et al (2012) a composição de uma cadeia produtiva não limita a apenas uma matéria-prima, tampouco a um produto final. De acordo com Staatz (1997), para se entender esta composição, e as relações entre os elos de uma cadeia produtiva devem ser considerados cinco conceitos chaves, que são: a verticalidade, a orientação por demanda, a coordenação dentro dos canais, a concorrência entre elos da cadeia e a alavancagem.

Conforme definido por Staatz (1997) verticalidade, significa admitir que as condições de um elo da cadeia são susceptíveis de ser influenciada pelas condições em outros elos, muitas vezes de forma inesperada e indireta. A orientação por demanda, significa compreender a dinâmica de possíveis mudanças na demanda pelo produto, tanto no mercado interno quanto internacional, e a implicação dessa mudança para os gestores, elos e desempenho da cadeia produtiva (STAATZ, 1997; BATALHA; SCARPELLI, 2005).

Na orientação por demanda, Pires (2009) ressalta que, existem fluxos contínuos de produtos seguem em direção aos consumidores, e outros fluxos de informações que partem dos consumidores até chegar ao alcance dos fornecedores, para que estes fluxos aconteçam de maneira eficiente, cada membro da cadeia deve desempenhar suas tarefas da melhor maneira possível, evitando desperdícios e funções duplicadas, facilitando o gerenciamento holístico que permite aproveitar as sinergias produzidas.

Com relação aos conceitos da coordenação dentro canais e da concorrência entre os elos da cadeia, Staatz (1997) e Batalha e Scarpelli (2005) afirmam que, o primeiro significa analisar o mercado atual, os contratos, a harmonização dos arranjos produtivos e as atividades dos agentes de uma cadeia produtiva; e o segundo ao fato que um determinado subsetor pode muitas vezes se utilizar de diversos canais de comercialização. Como em cadeias produtivas podem existir empresas de médio e pequeno porte, o conceito de alavancagem destacado por Staatz (1997), significa estudar e executar ações públicas que tenham por objetivo contribuir o desenvolvimento do maior número de empresas possíveis.

O entendimento da composição e as relações entre os elos de uma cadeia produtiva são importantes identificar os problemas dessa cadeia produtiva e sugerir mudanças para aumentar a competitividade. Para tanto são importantes profissionais e instrumentos que forneçam auxílio na avaliação das informações, visando dar condições as propriedades rurais de acompanhar a evolução do setor de agronegócio (AMARAL, 2011). 
Na concepção de Buainain e Batalha (2007) "com o crescimento do porte, da competitividade e, por consequência, da complexidade da agricultura brasileira nos últimos anos, o conhecimento virou uma ferramenta ainda mais essencial.” Em especial para as empresas rurais, que são aquelas que exploram a capacidade produtiva do solo, da criação de animais e da transformação dos produtos agrícolas (MARION, 2010). Os gestores das empresas rurais que atuam na pecuária brasileira, são carentes de ferramentas mais adequadas às suas especificidades, em função heterogeneidade das próprias propriedades e das formas de gestão adotadas (BUAINAIN; BATALHA, 2007).

A pecuária brasileira caracteriza-se pelo contraste existente entre propriedades altamente eficientes, que contam com gestão profissional e outras, menos eficientes, sem capacidade de investimento em melhoria de processos. Essa diversidade dos sistemas de produção na pecuária dificulta o desenvolvimento e reduz a amplitude de aplicação de ferramentas de gestão suficientemente genéricas para serem aplicadas em todos os tipos de sistemas existentes (BUAINAIN; BATALHA, 2007, p. 57).

O conjunto de agentes que a compõe a pecuária nacional apresenta grande heterogeneidade, de pecuaristas altamente capitalizados a pequenos produtores empobrecidos, de frigoríficos com alto padrão tecnológico, capazes de atender a uma exigente demanda externa, a abatedouros que dificilmente preenchem requisitos mínimos da legislação sanitária. Contudo, atualmente existe a convicção que a construção de sistemas e redes com inclusão de pequenos produtores, inovação e marketing pode trazer ao agronegócio a possibilidade de reduzir o desemprego e a pobreza nos países em desenvolvimento (CAMPOS; FAVA, 2007)

A implementação de políticas públicas, estratégias privadas e ações coletivas desenvolvidas por organizações do agronegócio contribuíram para o aumento da competitividade em sistemas agroindustriais. Entre essas ações, destacam-se as trocas de informações entre os agentes participantes, melhoramento da capacitação técnica, investimentos em inovação e investimentos em ação de marketing. Empresas estão se unindo para aumentar sua produtividade e sua força, estimulando o crescimento do consumo per capita e conquistando novos mercados (NEVES, 2005).

Essa postura foi observada na cadeia produtiva da carne suína, quando em 1994 a Associação Brasileira Criadores de Suínos (ABCS) implantou nova estratégia de marketing para reduzir os principais gargalos da comercialização da carne suína no 
Brasil. Tal estratégia ficou conhecida como Política Nacional de Marketing para a Carne Suína, com o lema "Um novo olhar sobre a carne suína” (ABCS , 2012).

North (1990) comparou a atitude das empresas em cadeias produtivas em ambiente institucional, com as regras de um jogo, onde as organizações são os “jogadores” desta partida. O autor considera que a interação da empresa com a sociedade não depende somente das regras do ambiente, mas também das ações que realizam, como por exemplo estratégias de marketing ou planejamento tributário. Assim, em uma cadeia produtiva para que as empresas atingirem objetivos comuns, precisam coordenar suas ações, e a entidade coletiva formada pela união dessas organizações ofereça maior competitividade à cadeia produtiva (NORTH, 1990).

Mance (2012), ao estudar as ligações e fluxos de materiais envolvidos nas cadeias produtivas, identificou que a reorganização das cadeias produtivas baseadas na solidariedade, substitui os fornecedores de insumos que operam de acordo com a lógica do capital, com fornecedores que operam de acordo com a lógica da economia solidária, trocando insumos produzidos de uma forma não-ecológica com outros desenvolvidos de forma ecologicamente sustentável. Isso torna possível corrigir o fluxo de valor, cada vez que habilita a economia solidária e promovendo um desenvolvimento socialmente justo e ecologicamente sustentável.

\section{METODOLOGIA}

No ano de 2010 a ACRISMAT em parceria com o Instituto Mato-grossense de Economia Agropecuária (IMEA), pesquisadores da Universidade Federal de Mato Grosso (UFMT) e do Núcleo de Extensão e Pesquisas Econômicas e Contábeis (NEPEC), realizaram pesquisa de campo com o objetivo de conhecer melhor a suinocultura de MT, identificando os fatores positivos e negativos enfrentados pelos produtores e empresas.

A ACRISMAT utilizou a metodologia rapid appraisal (RA). O método RA é recomendado para a avaliação do desempenho de sistemas e se mostra apropriado nos casos em que é necessária a compreensão das relações de causa e efeito que afetam o comportamento do sistema. As informações podem ser obtidas por meio formal ou informal, ou pela combinação dos dois. Valorizam-se as informações de fontes secundárias, que devem ser levantadas em etapa inicial da pesquisa (SILVA; SOUZA FILHO, 2007). O método RA pode ser obtido com maior nível de detalhamento em 
bibliografias como: Kumar (1993), Pattanayak (2004), Silva e Souza Filho (2007), Melz (2010), USAID (2010), Freudenberger (2011).

A pesquisa da ACRISMAT, foi aplicada diretamente aos produtores, cooperativas, frigoríficos e associações pertencentes ao segmento da suinocultura, ou seja, agentes-chaves da cadeia produtiva. Todos os questionários desta pesquisa foram analisados e tabulados de forma a criar um banco de dados, observando informações como regiões de estudo, dados das propriedades, custos de produção, tipo de granja, sistema de produção, quantidade de animais por etapa de criação, genética, fase de criação, etc.

Este banco de dados produzido foi utilizado para caracterizar a cadeia produtiva da suinocultura no estado de Mato Grosso. Porém, houve necessidade de se complementar estas informações. Assim, durante a realização da pesquisa, foram realizadas visitas técnicas, entrevistas com cooperativas, entrevistas com frigoríficos e especialistas sobre produção de suínos.

Quadro 01 - Regiões e municípios pesquisados pela ACRISMAT, no estado de Mato Grosso, em 2010.

\begin{tabular}{|l|l|l|l|}
\hline REGIÃO & MUNICÍPIO & REGIÃO & MUNICÍPIO \\
\hline $\begin{array}{l}\text { 1-Tangará da } \\
\text { Serra }\end{array}$ & Brasnorte & 3-Sinop & Alta Floresta \\
\hline & Campo Novo & & Santa Carmem \\
\hline & Diamantino & & Sinop \\
\hline & Juína & $\begin{array}{l}\text { 4-Lucas do Rio } \\
\text { Verde }\end{array}$ & Lucas de Rio Verde \\
\hline & Tangará da Serra & & Tapurah \\
\hline & Pedra Preta & 5-Sorriso & Sorriso \\
\hline & Poxoréu & & Vera \\
\hline & Primavera & 6- Nova Mutum & Nova Mutum \\
\hline & Rondonópolis & & $\begin{array}{l}\text { Santa Rita de } \\
\text { Trivelato }\end{array}$ \\
\hline
\end{tabular}

Fonte: adaptado de ACRISMAT, 2010

Foram consideradas como amostra as microrregiões com maior representatividade na produção de suínos em MT, que foram: Alto Teles Pires, Sinop, Primavera do Leste, Parecis, Rondonópolis e Tangará da Serra. Nessas microrregiões foram selecionados os municípios nos quais existem granjas de suínos. Os dados tabulados de forma a permitir analisar o tipo de granja, sistema de produção, e proximidade geográfica. O Quadro 01 apresenta as regiões e municípios, amostrados pela ACRISMAT. 
Com relação à amostragem dos produtores, a base de dados analisada foi composta por 81 produtores de diferentes tipos de sistemas de criação e tipos de granjas nas diferentes regiões, conforme Tabela 01, e nove frigoríficos que processam a carne suína no estado de Mato Grosso.

Tabela 01- Número de granjas de suínos, por sistema de criação utilizado e por tipo de granja, no estado de Mato Grosso, 2010.

\begin{tabular}{ccccccccc}
\hline $\begin{array}{c}\text { Sistema de } \\
\text { Criação }\end{array}$ & $\begin{array}{c}\text { CC } \\
*\end{array}$ & $\begin{array}{c}\text { CC e } \\
\text { GRSC }\end{array}$ & $\begin{array}{c}\text { GRSC* } \\
*\end{array}$ & $\begin{array}{c}\text { UPL } \\
* *\end{array}$ & $\begin{array}{c}\text { UPL e } \\
\text { GRSC }\end{array}$ & $\begin{array}{c}\text { UPL e } \\
\text { UT }\end{array}$ & $\begin{array}{c}\text { UT**** } \\
*\end{array}$ & $\begin{array}{c}\text { Tota } \\
\mathbf{1}\end{array}$ \\
\hline Integrado & 1 & & & 3 & 1 & 1 & 16 & 22 \\
\hline Cooperado & 1 & 1 & & 1 & & & 10 & 13 \\
\hline $\begin{array}{c}\text { Independent } \\
\text { e }\end{array}$ & 25 & 2 & 1 & 10 & 1 & & 7 & 46 \\
\hline Total & $\mathbf{2 7}$ & $\mathbf{3}$ & $\mathbf{1}$ & $\mathbf{1 4}$ & $\mathbf{2}$ & $\mathbf{1}$ & $\mathbf{3 3}$ & $\mathbf{8 1}$ \\
\hline
\end{tabular}

*Ciclo Completo, **Granjas de Reprodutores Suídeos Certificada, ***Unidades de Produção de Leitões, ****Unidades de Terminação

Fonte: adaptado de ACRISMAT, 2010

Com base nos dados da ACRISMAT foi possível trabalhar com o conceito de cadeia produtiva constitui aplicação do entendimento de sistemas e processos produtivos que vão desde as matérias-primas, pelo uso de equipamentos, pela incorporação de produtos intermediários e chega até o produto final, distribuído por rede de comercialização. Dessa forma, conceitua-se a cadeia de produtiva como um conjunto de atividades estreitamente interligadas (produção, processamento, distribuição, consumo) e relacionadas verticalmente por pertencerem a um mesmo produto ou a um produto semelhante (MONTIGAUD, 1991).

Com relação a estrutura da cadeia produtiva, esta pesquisa utilizou como base a representação dos segmentos da cadeia produtiva da suinocultura no Brasil desenvolvida pelos autores Miele e Waquil (2007a), conforme Figura 1.

Figura 1 - Representação sintética da cadeia produtiva da carne suína, no Estado do Mato Grosso.

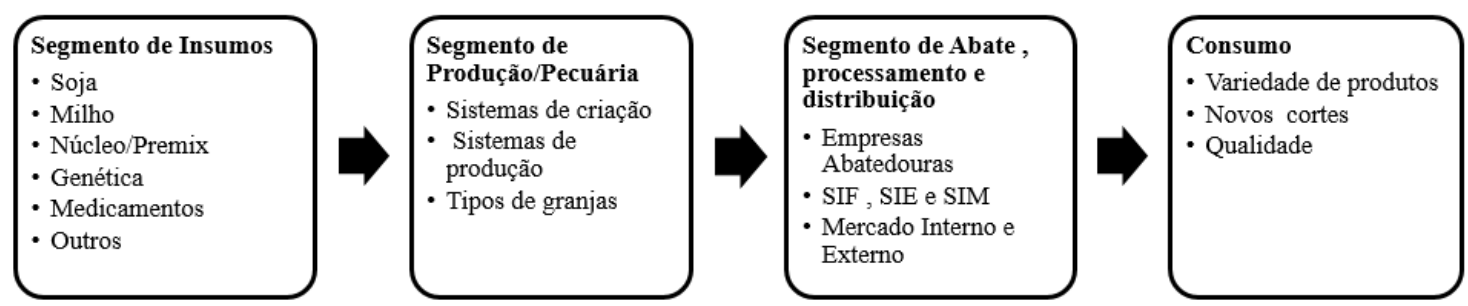

Fonte: adaptado de Miele e Waquil (2007a) 
Visualizar a cadeia da suinocultura como um grande sistema de produção, vocacionado para a produção de produtos de qualidade, é importante para traçar estratégias mais realistas para sua gestão. Da mesma forma, conhecer os segmentos e estabelecer as interações de seus subsistemas componentes é fundamental para melhorar o desenvolvimento e o desempenho dos setores. Pode-se dividir a cadeia da suinocultura em cinco subsistemas ou segmentos: insumos, abate e processamento, distribuição e consumo. O segmento de consumo não será abordado, por uma questão de limitação de estudo.

\section{RESULTADOS}

\subsection{Segmento de insumos}

A propriedade suinícola é uma unidade de produção, que precisa operar de forma organizada para gerar um resultado econômico que remunere os investimentos e obtenha lucro (EMBRAPA, 2011). Dessa forma, o cuidado com os insumos em especial de alimentação e medicação podem garantir o sucesso da atividade, desde que adotados métodos eficientes de gerenciamento, e controle de custo de produção (MIELE; WAQUIL, 2007b).

Em especial durante o processo de compra dos insumos é que os produtores realmente se preocupam com o custo de produção. Os principais insumos agrícolas usados na suinocultura são: milho, farelo de soja e farelo de trigo. Além destes insumos são utilizados também em algumas granjas: farelo de carne, minerais, medicamentos e vitaminas, premix, núcleo e ração pronta (ACRISMAT, 2010).

O milho e o farelo de soja são os principais componentes da ração e como a alimentação é responsável por 70 a $80 \%$ do custo total de produção do suíno vivo, a ração é um componente que influencia significativamente na competitividade da produção. O milho, em especial, pode representar até $40 \%$ do custo de produção do suíno vivo (SARAIVA, 2012).

A disponibilidade de grãos, reflete a vantagem competitiva da atividade em Mato Grosso. Na safra de 2009/2010, o estado registrou produção recorde de milho, 8,1 milhões de toneladas, correspondente a 14,5\% da produção nacional. O estado do Mato Grosso é responsável por 35\% da produção nacional de milho na safra de inverno, contudo apresenta baixa participação na produção da safra de verão. Isso decorre do fato de que a cultura do milho é rotacionada com a soja. Assim, a soja é 
plantada na safra de verão e o milho é plantado na safra de inverno (DUARTE; GARCIA; MIRANDA, 2011).

De maneira geral os Estados da região Centro-Oeste merecem destaque, pois obtiveram produtividades médias altas, mesmo com a predominância da safra de inverno na produção. Consequência da produção do milho em áreas grandes, e do uso de tecnologias modernas, sementes de alta qualidade e potencialidade, o que favorece ao crescimento da produtividade desses estados. A suinocultura permite a ampliação do parque industrial ao utilizar o milho como insumo (DUARTE; GARCIA; MIRANDA, 2011).

$\mathrm{Na}$ alimentação de suínos, a soja participa como fonte protéica, na forma de farelo, subproduto da extração do óleo. O farelo de soja é o segundo maior ingrediente na fabricação de rações. O uso da soja em sua forma integral encontra restrições, especialmente pela presença de fatores antinutricionais. Os produtores de soja normalmente vendem a produção para as indústrias, e estas vendem o farelo de soja para as propriedades suinícolas. Para produzir uma tonelada de farelo de soja são necessários $1.267 \mathrm{~kg}$ de soja, pois foi considerado um rendimento de $79 \%$ de farelo e $21 \%$ óleo (ZARDO; LIMA, 1999; DUARTE; GARCIA; MIRANDA, 2011).

Em relação à participação do estado de MT na produção de soja, tem-se que em 2012/2013 o volume produzido em MT correspondeu a 9\% da produção mundial (CONAB, 2013). O estado é responsável por 28\% da área plantada do Brasil e por $37 \%$ da produção nacional (91,1 milhões de toneladas). A grande extensão territorial, solo fértil, técnicas produtivas e seu clima tropical favorecem efetivamente no desenvolvimento dessa cultura no estado de MT (LOPES, 2013).

Dados da Associação dos Produtores de Soja e Milho de Mato Grosso (APROSOJA), revelam que as regiões com maiores participações de produção do estado são as do Médio-Norte (39\%), do Sudeste (20\%), do Nordeste (15\%) e do Oeste (13\%). Na safra de 2013/14 o volume produzido no estado de MT foi de 26,29 milhões de toneladas, com área plantada de 8,5 milhões de hectares e produtividade de 51,9 sacas por hectares (CONAB, 2013).

Como o milho e a soja não oferecem todos os nutrientes que um suíno precisa, é necessário o uso de aminoácidos sintéticos na alimentação. Para tanto é utilizado o Núcleo, que é definição genérica para uma mistura que contém minerais, vitaminas e promotores de crescimento, e geralmente é misturado aos ingredientes, com alimento 
energético associado, ao concentrado protéico. O uso do núcleo dispensa a inclusão de outras fontes minerais de cálcio, fósforo e sódio. (LUDKE et al, 1997)

Outra observação de Fávero (2003, p.1) é que:

A obtenção de lucros também exige a combinação adequada dos ingredientes para compor dietas balanceadas nutricionalmente, para cada fase de produção, visando atender as exigências nutricionais específicas. Em termos médios, em uma granja estabilizada de ciclo completo, para cada porca do plantel produzindo 20 leitões ao ano, terminados até os $105 \mathrm{~kg}$ de peso de abate, é necessário dispor de $7.000 \mathrm{~kg}$ de ração com um gasto médio de $240 \mathrm{~kg}$ de núcleo, $5.260 \mathrm{~kg}$ de milho e $1.500 \mathrm{~kg}$ de farelo de soja. Ainda, considerando uma relação média de 2,8 litros de água potável ingerida para cada kg de ração consumida, estima-se um gasto anual de 19,6 mil litros de água potável para cada porca e sua produção.

Tabela 2- Market share das empresas de genéticas, nas granjas de suínos no estado de Mato Grosso, 2010.

\begin{tabular}{cc}
\hline Empresas de genética & \% \\
\hline Agroceres PIC & $29 \%$ \\
Sadia & $14 \%$ \\
Genetic Pork & $21 \%$ \\
DB Genética Suína & $19 \%$ \\
Topiges & $4 \%$ \\
Daulant & $3 \%$ \\
Embrapa & $7 \%$ \\
Porco Light & $1 \%$ \\
Penalam & $1 \%$ \\
\hline Total & $\mathbf{1 0 0 \%}$
\end{tabular}

Fonte: adaptado de ACRISMAT, 2010

A base tecnológica da produção dos suínos é a qualidade genética dos reprodutores, disso depende o desempenho de uma raça ou linhagem. A forma mais viável de promover o aumento da produtividade é não só a melhor nutrição, mas principalmente a adequada capacidade genética, ou potencial genético como é normalmente chamado. No Brasil encontram-se instaladas empresas de multiplicação que importam as avós e desenvolvem essa genética, com objetivo de obter reprodutores comerciais adaptados às características locais (FÁVERO, 2003; SARAIVA, 2012).

No Mato Grosso as principais empresas de genéticas são: Agroceres PIC, Genetiporc (Canadá), multiplicação desenvolvida pela Ideal Porc, DB-DanBred 
(Dinamarca), Sadia, Embrapa, Topigs (Inglaterra e Holanda), Dalland (Austrália). A Tabela 2 apresenta a participação destas empresas no estado de Mato Grosso (ACRISMAT, 2010). No ano de 2013, MT começou a exportar suínos reprodutores para Argentina.

\subsection{Segmento de produção}

Um sistema de produção de suínos, chamado de "granja de suínos", é constituído por conjunto inter-relacionado de componentes ou variáveis organizadas que tem como objetivo básico a produção de suínos. O desempenho de uma granja depende da harmonia entre as variáveis de "entrada" que determinam a capacidade de produção do sistema (NICOLAIEWSKY et al, 1998).

O produtor é responsável pela condução do sistema formado por animais, edificações, equipamentos, alimentação e meio-ambiente, e deve levar em conta todos estes fatores ao administrar a produção em uma granja. Além disso, deve considerar o tamanho da granja, e quais os métodos e tipos de criação a serem utilizados (CARVALHO; VIANA, 2011).

Com relação aos modelos de sistema de criação, estes podem ser extensivos ou intensivos. Na forma extensiva os animais são criados à solta, sem a preocupação com a produtividade ou controles técnicos sobre a produção, e suínos de diferentes idades disputam, entre eles, o alimento. Muito observado em pequenas criações de suínos caracterizadas como de subsistência e voltada para o autoconsumo com baixo nível tecnológico (NICOLAIEWSKY et al, 1998; CARVALHO; VIANA, 2011).

Segundo Dietze (2011) esse sistema de criação é viável e pode ser facilmente adotado e adaptado por pequenos agricultores. Os porcos requerem pouco investimento inicial; são bons conversores de alimentos em carne em comparação com outros animais, como gado. Além disso, fornecem dieta mais variada para a família rural, e quase todas as partes do suíno podem ser consumidas pelas famílias ou vendidas.

$\mathrm{Na}$ criação intensiva tem-se a preocupação com a produtividade, acumulando trabalho e capital em espaço pequeno. O produtor apresenta maior conhecimento e as instalações funcionam como abrigos contra fatores climáticos e piquetes de contenção. Os animais são separados por idade e sexo e o manejo reprodutivo é feito através da seleção dos animais no plantel (SILVA FILHA et al, 2005) 
Uma das modalidades do sistema intensivo é o Sistema intensivo de suínos criados ao ar livre (SISCAL), que apresenta baixo custo de implantação e manutenção, número reduzido de edificações, facilidade na implantação e na ampliação da produção, mobilidade das instalações e redução do uso de medicamentos. Pode ser considerado como alternativa para quem quer ingressar na produção de suínos ou aumentar a sua produção e não dispõe de recursos financeiros (NICOLAIEWSKY et al, 1998; CARVALHO; VIANA, 2011). Segundo ACRISMAT (2010) apenas 4\% das empresas no estado de Mato Grosso utilizam o SISCAL.

De acordo com dados da ACRISMAT (2010), o sistema mais utilizado pelas empresas de MT é o Sistema Intensivo de Suínos Confinados (SISCON), encontrado em $95 \%$ das granjas do estado, no ano de 2010. Todas as categorias estão sobre piso e cobertura. E as fases da criação geralmente podem ser desenvolvidas em diferentes prédios. Permite a mecanização do fornecimento de ração e limpeza, com maior economia de mão de obra. Além disso, é possível nesse sistema ter criações confinadas de alta, média e baixa tecnologia.

Das principais regiões produtoras de suínos cerca de $76 \%$ são tecnificadas. Estas granjas estão concentradas nas regiões de Lucas do Rio Verde com 25,90\% e Nova Mutum (composta pelos municípios de Santa Rita do Trivelato e Nova Mutum) com 14,80\%. As granjas que não possuem tecnificação ou são semitecnificadas geralmente possuem ligações com empresa integradora ou granja cooperada que desempenha a maioria das funções produtivas (ACRISMAT, 2010). A Tabela 3 apresenta a distribuição das granjas quanto à tecnificação no estado de MT, no ano de 2010.

Dados da ACRISMAT (2010) apontam que 32\% das granjas são do tipo CC, e $17 \%$ do tipo UPL, nas principais regiões produtoras, de suínos do estado de Mato Grosso.

Tabela 3- Percentual de granjas por tecnificação, nas principais regiões produtoras em Mato Grosso em 2010.

\begin{tabular}{lccccccc}
$\begin{array}{c}\text { Tecnificação } \\
\text { da Granja }\end{array}$ & $\begin{array}{c}\text { Lucas } \\
\text { do Rio } \\
\text { Verde }\end{array}$ & $\begin{array}{c}\text { Nova } \\
\text { Mutum }\end{array}$ & Rondonópolis & Sinop & Sorriso & $\begin{array}{c}\text { Tangará } \\
\text { da } \\
\text { Serra }\end{array}$ & Total \\
\hline Tecnificada & $25,90 \%$ & $14,80 \%$ & $12,30 \%$ & $4,90 \%$ & $16,00 \%$ & $2,90 \%$ & $76,80 \%$ \\
Não tecnificada & & $1,20 \%$ & $2,50 \%$ & $8,60 \%$ & $1,20 \%$ & $4,90 \%$ & $18,40 \%$ \\
Semi & $1,20 \%$ & & $1,20 \%$ & & $1,20 \%$ & & $3,60 \%$ \\
tecnificada & & & & & & &
\end{tabular}




\begin{tabular}{cccccccc} 
Não respondeu & $1,20 \%$ & & & & & & $1,20 \%$ \\
\hline Total & $\mathbf{2 8 , 3 0 \%}$ & $\mathbf{1 6 , 0 0 \%}$ & $\mathbf{1 6 , 0 0 \%}$ & $\mathbf{1 3 , 5 0 \%}$ & $\mathbf{1 8 , 4 0 \%}$ & $\mathbf{7 , 8 0 \%}$ & $\mathbf{1 0 0 , 0 0 \%}$
\end{tabular}

Fonte: Adaptado de ACRISMAT (2010)

Outro fator a ser considerado são os tipos de produção definidos pelo tipo de produto a ser comercializado ou pelas fases de criação existentes na propriedade. $\mathrm{O}$ processo produtivo pode ocorrer em quatro tipos diferentes de estabelecimento de criação: Ciclo Completo (CC), Unidades de Produção de Leitões (UPLs), Unidades de Terminação (UTs) e Granjas de Reprodutores Suídeos Certificada (GRSC).

Nas granjas de CC são desenvolvidas no mesmo estabelecimento todas as fases de produção do animal. É um tipo de criação que abrange todas as fases (reprodução, maternidade, creche e terminação) e que tem como produto o suíno terminado (NICOLAIEWSKY et al, 1998).

Todos os outros tipos de criação são especializações quando comparadas ao CC. De acordo com Amaral et al (2006), nas UPLs são desenvolvidas basicamente as fases de reprodução (inseminação, maternidade, desmame e creche) produzindo leitões. Podem produzir leitões desmamados que tem em média $6 \mathrm{Kg}$ (21 dias) ou 10 $\mathrm{Kg}$ (42 dias), ou produzir leitões para terminação com 22 a $28 \mathrm{Kg}$ ou 50 a 70 dias de idade. No peso ou tempo adequado os suínos são transferidos para as UTs, onde são engordados até atingir o peso de abate, entre $100 \mathrm{~kg}$ e $130 \mathrm{~kg}$, sendo destinados aos abatedouros ou frigoríficos (SARAIVA, 2012). Em MT as UTs ocupam 48\% das granjas, das principais regiões produtoras (ACRISMAT, 2010). Esta fase é extremamente importante mais de $60 \%$ do custo de produção ocorre após esse período, ou seja, os cuidados entre investimentos e eficiência precisam ser redobrados, isso devido ao fato de tratar-se do período de maior consumo de ração, onde ocorre a maior deposição de gordura nas carcaças dos animais. Na etapa do processo produtivo é onde as mortes causam prejuízos maiores, e onde as doenças se manifestam com maior intensidade, exigindo maior vigilância ao controle da Segurança Alimentar (MEINCKE, 2010).

Nessa etapa define-se o retorno financeiro das carcaças, uma vez que o último mês de terminação representa $16 \%$ do tempo de vida e $29 \%$ do consumo de ração, considerando-se um suíno de $120 \mathrm{~kg}$ de peso com 170 dias de idade (MEINCKE, 2010). Contudo, as variações nas taxas de crescimento dos suínos na fase de terminação causam frequentes perdas em quantidade e qualidade. Deve-se evitar que animais mais leves disputem o alimento com animais mais pesados, então a eficiência 
na utilização das instalações a chamada "capacidade de utilização" pode definir a lucratividade dos produtores, tornando o manejo, a qualidade das instalações e a especialização da mão de obra fundamentais para o sucesso da atividade nesta fase (ALMEIDA, 2008).

As granjas GRSC são estabelecimentos oficialmente certificados e monitorados, onde são criados ou mantidos suínos para comercialização ou distribuição, com a finalidade de reprodução. Para garantir a certificação, as granjas devem ser livres da peste suína clássica, da doença de Aujeszky, brucelose, tuberculose, sarna e livre ou controlada para leptospirose (MENEGUETTI, 2000; ROCHA, 2006; MIELE; WAQUIL, 2007a).

Segundo Instituto Brasileiro de Geografia e Estatística (IBGE, 2012) a distribuição geográfica do rebanho de suínos em MT encontra-se pulverizada pelo território, com regiões que apresentam alto índice de adensamento, como a mesorregião Norte, com $72,8 \%$ do rebanho e a Sudeste, com 12,5\% do rebanho estadual.

Os principais municípios produtores em MT segundo o IBGE (2012) são eles: Tapurah (304.000 cabeças), Lucas do Rio Verde (151.350 cabeças), Vera (147.084 cabeças), Ipiranga do Norte (133.837), Nova Mutum (118.216 cabeças) e Sorriso (115.500). Juntos estes municípios foram responsáveis por 54\% do rebanho de MT em 2012. Outra aglomeração de suinocultores encontra-se localizada na região sudeste de MT, ao longo da BR-070, tendo como principais produtores os municípios de Campo Verde (94.301 cabeças), Rondonópolis (22.000 cabeças), Poxoréo (31.279 cabeças) e Primavera do Leste (17.446 cabeças).

Existem três formas de sistemas de produção: o integrado, o independente e o cooperativo. O sistema independente é utilizado por $57 \%$ das empresas localizadas nas principais áreas produtoras de MT, em especial nos municípios de Sinop, Sorriso e Tapurah (ACRISMAT, 2010). O produtor independente executa todas as fases, não possuindo vínculo com agroindústrias. A compra de animais reprodutores e insumos (alimentos e produtos veterinários) no mercado ocorrem sem fornecedor fixo. Dessa forma, as empresas produtoras, no caso os próprios suinocultores, compram todos os insumos necessários à produção, desenvolvem o produto e o vendem no mercado, assumindo mais riscos e utilizando capital de giro próprio (FÁVERO, 2003; ROCHA et al, 2007). 
Na região Sudeste de MT tem-se o predomínio do sistema de produção independente (ACRISMAT, 2010). Nestes casos a produção é comercializada no mercado spot, sem vínculo com empresa integradora ou cooperativa. A produção dessa região destina-se principalmente para os abatedouros instalados em Rondonópolis, Primavera do Leste, Cuiabá e Goiás. Esse sistema também pode ser observado no município de Diamantino, com o Grupo Carroll's Food do Brasil, este grupo é associado aos frigoríficos Marfrig e Mabella (SARAIVA, 2012).

O sistema integrado caracteriza-se pela presença de empresa abatedora ou processadora que tem a função de integrar verticalmente várias fases do processo produtivo, nutrição, como melhoramento genético, abate dos animais e processamento da carne, além de fornecer o aparato necessário à criação dos animais pelos suinocultores, geralmente sob a forma de contrato (ROCHA et al, 2007). Esse sistema é identificado em especial na região da BR-163, nos municípios de Lucas do Rio Verde, Tapurah, Sorriso e Nova Mutum com as granjas integradas pelas empresas Sadia e Perdigão (ACRISMAT, 2010).

No sistema de cooperativas, destaca-se no estado de MT a região Médio Norte. Existem quatro cooperativas com representatividade de produção no estado de Mato Grosso, que são a Ideal Porc Suinocultura, a Cooperativa Agropecuária Mista de Nova Mutum (Coopermutum), a Cooperativa dos Produtores de Suínos de Sorriso (Suinocoop) e a Cooperativa Agroindustrial de Lucas do Rio Verde (Coagril). Estas cooperativas estão situadas nos municípios de Nova Mutum, Sorriso, Lucas do Rio Verde (ACRISMAT, 2010).

A Ideal Porc Suinocultura, fornecedora de genética, é a empresa que compõe a cooperativa de suinocultores Intercoop. A Coagril é formada por 21 produtores, e possui relações com as empresas Vitagri (especialista em nutrição) e a Genetiporc, empresa Canadense de genética de suínos. Os leitões permanecem na cooperativa até serem transferidos para as propriedades dos associados, encarregados do processo de engorda para o abate. A produção destina-se ao frigorífico da Sadia (SARAIVA, 2012).

\subsubsection{Caracterização dos produtores}

Os produtores do estado de Mato Grosso efetivaram profundas transformações na atividade principalmente nos últimos dez anos. A diversidade de origem destes produtores enriquece a troca de conhecimento referente à forma de produção e 
evidencia a forte tendência de mudança das áreas de produção para regiões não tradicionais na atividade (ABCS, 2012). Segundo dados da ACRISMAT (2010) a maioria dos entrevistados migrou da região sul do Brasil, sendo que 24,7\% se originam do estado de Santa Catarina, 21\% do Rio Grande do Sul e 12,3\% do Paraná, estados com ampla participação na produção nacional de carne suína.

Esses produtores estão distribuídos nas principais regiões produtoras de MT, e contribuem com conhecimentos referentes a fatores como nutrição, sanidade animal, manejo e aprimoramento gerencial da granja. Essa migração da atividade tem ocorrido principalmente por causa da grande produção de grãos, e redução das criações extensivas devido à disponibilidade de novas tecnologias de produção (CARVALHO et al, 2012).

Com base nos dados da ACRISMAT (2001), observa-se que cerca de 53\% dos produtores estão na atividade há mais de 10 anos e $44 \%$ não residem na propriedade. Com relação à escolaridade e aprimoramento para exercer a atividade, $23 \%$ possuem ensino médio completo, $25 \%$ o ensino superior completo e $64,2 \%$ afirmam buscar novos conhecimentos constantemente.

Em resumo os responsáveis pela maior parcela da produção mato-grossense deste segmento são na maioria produtores de pequeno e médio porte (ACRISMAT, 2010). Lopes, Reis e Yamaguchi (2007) afirmam que pequenos produtores possuem capacidade limitada de beneficiamento e negociação direta da produção com os frigoríficos, enfrentando dificuldades de manterem-se competitivos no mercado, sendo intermediados na maioria das vezes pela empresa integradora ou cooperativa. Os grandes produtores, ao contrário, possuem capacidade de produção e negociam diretamente sua produção no mercado interno e externo.

Tabela 4- Percentual por pontos fortes da cadeia produtiva, na visão dos produtores de suínos, no estado de Mato Grosso, 2010.

\begin{tabular}{cccc}
\hline Pontos Fortes & $\mathbf{\%}$ & Pontos Fortes & $\%$ \\
\hline Matéria Prima (Barata) & $32,62 \%$ & Mão de obra (Barata) & $2,14 \%$ \\
\hline Bom Clima & $13,37 \%$ & Muitos Animais & $2,14 \%$ \\
\hline Localização & $8,56 \%$ & Instalação Adequada & $1,60 \%$ \\
\hline Genética do animal & $6,95 \%$ & Alimentação Barata & $0,53 \%$ \\
\hline Sanidade & $6,95 \%$ & Atividade Principal & $0,53 \%$ \\
\hline Áreas para dejetos & $6,42 \%$ & Bom Preço & $0,53 \%$ \\
\hline Bons Lucros & $4,28 \%$ & Concorrência entre Frigorificos & $0,53 \%$ \\
\hline Equipamentos & $4,28 \%$ & Estrutura & $0,53 \%$ \\
\hline Assistência Técnica & $3,74 \%$ & Logística & $0,53 \%$ \\
\hline
\end{tabular}




\begin{tabular}{cccc}
\hline Diversificação & $3,21 \%$ & Parcerias & $0,53 \%$ \\
\hline & Total & & $\mathbf{1 0 0 \%}$ \\
\hline
\end{tabular}

Fonte: Adaptado de ACRISMAT (2010)

$\mathrm{Na}$ tabela 4, tem-se a visão dos produtores com relação aos pontos fortes da cadeia produtiva. Dentre os que mais se destacam foram o baixo preço da matéria prima $(32,62 \%)$, clima favorável à produção $(13,37 \%)$ e a localização do estado de MT $(8,56 \%)$. Outro ponto importante destas informações é que a logística e as parcerias, não foram apontadas por muitos produtores como pontos fortes, e resultados similares foi encontrado em Couto et al (2006) que analisando os pontos fortes e fracos e as inter-relações entre os elos da cadeia produtiva de frutas orgânicas do Estado de São Paulo, identificaram que logística como um dos elos mais fraco da cadeia, constatando ainda a falta de integração entre alguns elos e a falta de informação por parte dos consumidores.

Esse perfil é importante para caracterizar os principais agentes da cadeia produtiva responsáveis pela geração de emprego e renda garantindo a subsistência de várias famílias (produtoras ou não), assegurando a alta demanda de matéria prima do mercado interno.

\subsection{Segmento de abate e processamento}

O abate e processamento de suínos envolvem um complexo sistema, com participação de instituições públicas e privadas, de diferentes segmentos, inclusive conhecimento das fundamentações legais relativo a procedimentos sanitários. Gerenciar esse sistema dentro e fora das granjas representa um grande desafio para a cadeia produtiva da suinocultura. As diferentes funções e atividades, de genética, recursos materiais e financeiros, nutrição e terminação com procedimentos padronizados, resultam em um processo de abate mais seguro do ponto de vista alimentar e no desenvolvimento de instrumentos eficazes para posterior distribuição do produto (PACHECO, 2006).

As instituições da cadeia visam a harmonização de procedimentos, com o objetivo de melhoria da qualidade e da transparência das informações para maior segurança alimentar, especialmente aquelas relacionadas ao atendimento às ocorrências zoossanitárias. Esses cuidados possibilitam a manutenção e a melhoria da condição sanitária dos rebanhos brasileiros, fornecendo credibilidade perante 
importantes países consumidores de produtos pecuários (AMARAL et al, 2006; MAPA, 2013).

Como descrito por Saraiva (2012), os segmentos de abate e processamento são constituídos por empresas e cooperativas de suínos. As empresas atuantes nestes segmentos são registradas em três diferentes subsistemas de inspeção, que certificam a qualidade do produto: sistema de inspeção federal (SIF), estadual (SISE) e municipal (SIM). De acordo com dados da Associação Brasileira das Indústrias Exportadoras de Carnes (ABIEC, 2015), no estado de Mato Grosso existem 18 frigoríficos registrados no SIF, 6 trabalham abate de suínos e estão localizados nos municípios de Lucas do Rio Verde (Sadia S/A), Nova Mutum (INTERCOOP), Nova Xavantina (IFC Internacional), Rondonópolis (Agra Agroindustrial), e dois em Cuiabá (JBS S/A).

Empresas registradas no SIF operam sob regras sanitárias mais rígidas, permitindo a comercialização do produto no mercado nacional e, se habilitada, pode comercializar no mercado internacional (MAPA, 2011). Já as empresas registradas no SISE e SIM podem comercializar seus produtos nos mercados estadual e municipal, respectivamente.

Dos 13 frigoríficos instalados em MT, os de maior capacidade de abate estão localizados nas regiões Norte, Sudeste e Nordeste. Estas regiões apresentam grande concentração do rebanho de suínos, o que favorece a comercialização e reduz os custos de transporte até o frigorífico (ACRISMAT, 2010). E até 2014, somente três frigoríficos de abate de suínos estavam registrados no Serviço de Inspeção Sanitária Estadual (SISE), devido ao maior rigor na fiscalização no período de 2010 a 2012, três frigoríficos tiveram seus registros no SISE suspensos e dois registros foram cancelados em MT (INDEA, 2014).

\subsection{Segmento de distribuição}

Em resumo, além de saber como e quanto produzir, os empresários precisam definir com eficiência para quem vender a produção. Nas decisões de médio e longo prazos, o gerenciamento da distribuição do produto desempenha papel preponderante em função das constantes mudanças relativas à tecnologia, nos preços dos insumos e produtos e nas políticas agrícolas, que levam ao produtor a riscos e incertezas (FÁVERO, 2003). 
Quanto maior o desenvolvimento e a tecnologia envolvidos no processo produtivo, maior o valor econômico das terras no entorno dos centros urbanos, e mais distantes dos centros de consumo os alimentos são produzidos. Considerando a natureza perecível dos alimentos e as novas exigências do consumo, impõe-se a necessidade da produção em maior escala utilizando tecnologias que agreguem as características almejadas de valor e capazes de contrapor-se à perecibilidade natural que permita a comercialização e o consumo em condições seguras (BOOMEN, 2008).

A escolha e a capacidade de produção determinam as estratégias das operações logísticas de distribuição. Dessa maneira existe um trade-off entre os objetivos, a quantidade produzida, e os mercados a serem acessados, considerando a satisfação das prioridades competitivas definidas pela empresa. A questão está em decidir quais capacidades ou recursos estratégicos na distribuição serão mais úteis para a empresa (COSTA; ASSUMPÇÃO, 2008).

Outro ponto importante na distribuição da cadeia produtiva da suinocultura é a instabilidade dos preços devido à variação do custo dos insumos, dessa forma o mercado da carne suína apresenta ciclos de produção e comercialização. No período de preços favoráveis, os suinocultores retêm matrizes, provocando aumento da produção por um período de 3 a 4 anos, incorrendo em preços que se reduzem gradualmente. No período de preços desfavoráveis os suinocultores descartam matrizes a fim de reduzir os custos de produção, em consequência, em período posterior reduz-se a oferta de suínos, fazendo com que os preços se elevem, reiniciando ciclo de expansão (WEYDMANN et al, 2005; SARAIVA, 2012).

A distribuição das carnes e embutidos produzidos no estado de MT compreende não só o mercado interno, mas o externo também. Com relação à exportação, Pereira e Corassa (2014) ressaltam que as indústrias frigoríficas são cada vez mais exigentes em relação à garantia do bem-estar animal, com o propósito de proporcionar menor perda qualitativa e quantitativa da carne suína e principalmente atender os requisitos de qualidade internacional.

As transações para exportação da carne suína, em especial, envolvem os seguintes processos i) a granja produtora com insumos e tecnologias; ii) as instituições de fiscalização da sanidade animal; iii) os frigoríficos de abate; iv) operadores de serviços logísticos (como alguns portuários); v) despachantes aduaneiros vi) e o consumidor. Os três últimos são os atores que participam diretamente do escoamento do produto (SEBRAE, 2008). 
A etapa de distribuição ou transporte do suíno das propriedades para o frigorífico é estressante para os animais, segundo Pereira $(2014$, p. 7) é devido ao fato de:

Expor os animais a ruídos, cheiros desconhecidos, alterações de velocidade brusca do caminhão, diferentes temperaturas ambientais, vibrações, menor espaço social, individual e a interação com o homem, tais fatores levam a respostas comportamentais e fisiológicas que podem contribuir para redução do rendimento de carcaça e qualidade da carne, bem como do bem-estar animal.

Averós et al (2007), observaram que suínos submetidos a viagens curtas podem ficar mais estressados no momento do desembarque do que os transportados por longas distâncias, isso devido ao fato de que longas jornadas permitem a recuperação de parâmetros fisiológicos do estresse. Pereira (2014) analisa, portanto, que as frequências de abate de suínos nos mesmos municípios onde foram produzidos explicitam que o fator distância entre granja e abatedouro não é determinante para o destino dos animais, e que possivelmente o regime de produção (integração e cooperativas) ou a melhor valorização comercial pontualmente em determinado frigorífico são razões que poderiam explicar a escolha de determinado trajeto.

Quadro 02 - Locais de abate dos suínos, nas principais regiões produtoras, por município no Mato Grosso em 2010.

\begin{tabular}{|l|l|l|}
\hline REGIÃO & MUNICíPIO & Local de abate \\
\hline 1-Tangará da Serra & Brasnorte & Tangará da Serra, Nova Mutum, Belo Horizonte, Juína \\
\hline & Campo Novo & \\
\hline & Diamantino & Rondonópolis, Nova Mutum e Dourados \\
\hline & Juina & Juína, Nova Mutum, Tangará e Sinop \\
\hline & Tangara da Serra & Tangará da Serra, São Paulo, Nova Mutum \\
\hline & Pedra Preta & Diamantino, Rondonópolis \\
\hline & Poxorel & Rondonópolis \\
\hline & Primavera & Rondonópolis, Brasilia, São Paulo e Goiás \\
\hline & Rondonopolis & Rondonópolis, Tangará da Serra, Mato Grosso do Sul e Goiás \\
\hline & Alta Floresta & Sinop \\
\hline & Santa Carmem & Rondonópolis e Sinop \\
\hline & Sinop & Sinop, Rondonópolis, Sorriso \\
\hline & L-Lucas do Rio Verde & \\
\hline 5-Sorriso & Tapurá & Sinop, Rondonópolis, Lucas do Rio Verde, Nova Mutum \\
\hline & Sorriso & Rondonópolis, Sinop, Tapurah, Lucas do Rio Verde, Sorriso, Nova Mutum, Goiás \\
\hline 6- Nova Mutum & Vera & Rondonópolis, Sinop, Vera, Nova Mutum, Goiás \\
\hline & Nova Motum & Nova Mutum \\
\hline
\end{tabular}

Fonte: adaptado de ACRISMAT, 2010

O Quadro 2, apresenta os locais de destino de abate do suíno, dos principais municípios produtores do estado de MT. Segundo dados da ACRISMAT (2010) cerca de $92 \%$ dos suínos produzidos em MT foram vendidos dentro do próprio Estado, 
sendo que o município que os produtores mais apontaram como destino para abate foi o de Nova Mutum (22\%). Este percentual justifica-se pela força da Cooperativa Coopermutum que junto com a Coagril e produtores independentes formaram o Sistema Intercoop, destinando sua produção para destinos como Rússia e Hong Kong. A segunda cidade mais apontada foi Rondonópolis (21\%). Nestas cidades encontramse instalada as bases do frigorífico Excelência que exporta para países das Américas do Sul e Central, Europa e países orientais (ACRISMAT, 2010).

Tabela 5- Dez principais trajetos de suínos destinados ao abate produzidos no estado de Mato Grosso de 2008 a 2012.

\begin{tabular}{llrrr}
\hline ORIGEM & DESTINO & TOTAL & \% & KM \\
\hline Tapurah & Lucas do Rio Verde & 1.507 .685 & 15,99 & 99.18 \\
Diamantino & Rondonópolis & 822.414 & 8,72 & 422.3 \\
Lucas do Rio Verde & Lucas do Rio Verde & 813.443 & 8,63 & 0 \\
Nova Mutum & Nova Mutum & 776.894 & 8,24 & 0 \\
Sorriso & Lucas do Rio Verde & 764.255 & 8,11 & 63.16 \\
Diamantino & Nova Mutum & 378.247 & 4,01 & 123.14 \\
Tapurah & Nova Mutum & 289.461 & 3,07 & 152,01 \\
Vera & Sorriso & 255.944 & 2,72 & 62,24 \\
Nova Mutum & Lucas do Rio Verde & 239.471 & 2,54 & 97,16 \\
Vera & Nova Mutum & 227.314 & 2,41 & 219,49 \\
Outros & - & 3.351 .601 & 35,55 & - \\
\hline \multicolumn{1}{c}{ TOTAL } & & 9.426 .729 & 100 & \\
\hline
\end{tabular}

Fonte: PEREIRA (2014)

Pereira (2014) utilizando os dados de transporte de suínos para abate de janeiro de 2008 a dezembro de 2012 fornecidos pelo Instituto de Defesa Agropecuária do Estado de Mato Grosso (INDEA-MT), identificou que o número de vendas para abate dentro de MT, nesse período, apresentou crescimento médio anual de 19,83\%, já o número de suínos transportados para o abate de 2012 em relação a 2008, observou-se aumento de $100,62 \%$. Os percursos foram realizados com distâncias médias ponderadas de 205,74 km. Da mesma forma que na pesquisa da ACRIMAT (2010), os municípios mais apontados como destino, no estado de MT, foram Nova Nutum e Rondonópolis (Tabela 5). E os trajetos realizados com maior representatividade nesse período foram entre Campo Verde (MT) a São Gabriel do Oeste (MS) e Tangará da Serra a Rondonópolis (MT) no período avaliado. 
Tabela 6- Número e percentual de suínos para abate produzidos no estado de Mato Grosso e transportados por estado de destino de 2008 a 2012.

\begin{tabular}{crrrrrr}
\hline ANO & $\mathbf{2 0 0 8}$ & $\mathbf{2 0 0 9}$ & $\mathbf{2 0 1 0}$ & $\mathbf{2 0 1 1}$ & $\mathbf{2 0 1 2}$ & MÉDIA \\
\hline ESTADO & $\mathbf{N}^{\mathbf{0}}$ & $\mathbf{N}^{\mathbf{0}}$ & $\mathbf{N}^{\mathbf{0}}$ & $\mathbf{N}^{\mathbf{0}}$ & $\mathbf{N}^{\mathbf{0}}$ & \% \\
\hline DF & 5.696 & 12.382 & 16.139 & 22.574 & 19.266 & 0,77 \\
GO & 23.310 & 29.551 & 56.473 & 47.294 & 36.605 & 2,05 \\
MG & 178 & 18.487 & 980 & 828 & 4.770 & 0,29 \\
MS & 25.800 & 6.199 & 500 & 22.216 & 52.052 & 1,15 \\
MT & 1.099 .689 & 1.540 .713 & 1.890 .064 & 2.155 .978 & 2.237 .555 & 94,54 \\
PR & 6.883 & 943 & 1.731 & 3.228 & 4.863 & 0,22 \\
RO & 584 & 79 & 0 & 896 & 10.372 & 0,11 \\
SC & 0 & 0 & 875 & 0 & 0 & 0,01 \\
SP & 19.531 & 17.587 & 16.908 & 6.877 & 552 & 0,78 \\
TO & 0 & 0 & 679 & 2.309 & 1.210 & 0,04 \\
Outros & 0 & 0 & 0 & 1.914 & 3.409 & 0,05 \\
\hline TOTAL & 1.181 .671 & 1.625 .941 & 1.984 .349 & 2.264 .114 & 2.370 .654 & 100 \\
\hline
\end{tabular}

Fonte: PEREIRA (2014)

As exportações do estado de MT vêm sendo realizadas por frigoríficos instalados nos municípios de Cuiabá, Nova Mutum, Rondonópolis e Várzea Grande. Outro município que se destaca é o de Sinop (19\%), que possui os frigoríficos Frigoweber, e o grupo Alibem que exporta para países da África, Ásia, América Central, América do Sul e Oriente Médio. Este grupo também participou da distribuição da produção da região de Nova Mutum. (ACRISMAT, 2010)

Por oportuno, é importante considerar que muito da produção estadual segue para abate e distribuição em outros estados, conforme Tabela 6. No período de 2008 a 2012, segundo Pereira (2014), os suínos produzidos em MT também foram enviados para estados como Goiás (2,05\%), Mato Grosso do Sul (1,15\%), Minas Gerais $(0,29 \%)$, Distrito Federal $(0,77 \%)$ e São Paulo (0,78\%). Estes mesmos estados foram encontrados na pesquisa de campo da ACRISMAT (2010) e aparecem no Quadro 1, apresentado anteriormente.

No ano de 2014 quase 100 plantas industriais brasileiras receberam aval da Rússia para exportar diferentes produtos de origem animal ao país da Eurásia. Destas, 07 são de Mato Grosso, quatro para carne suína e duas possuem o chamado Serviço de Inspeção Federal (SIF) habilitadas para mais de um item. A decisão russa é importante para expandir a exportação da carne suína no ano de 2015, contudo deve ser tratada com cautela, uma vez que o serviço sanitário russo não detalha as razões que motivaram a abertura ao mercado brasileiro (NASCIMENTO, 2014). 


\section{CONCLUSÕES}

Este trabalho analisou a cadeia produtiva da suinocultura no estado de Mato Grosso, caracterizando os principais elos da cadeia produtiva, fornecendo dados referente aos sistemas de produção e tipos de granjas. Para tanto, foram utilizados dados fornecidos pela ACRISMAT (2010), visitas técnicas e entrevistas com especialistas em suinocultura. A literatura apresenta trabalhos referentes à cadeia produtiva da suinocultura nacional e do estado de Mato Grosso. Foram identificados trabalhos relacionados estruturas de contratos, mudanças tecnológicas e desempenho competitivo da cadeia. No entanto, o trabalho proposto pode ser considerado pioneiro por descrever com detalhes a cadeia produtiva em seus diversos segmentos.

Com relação à problemática abordada, foi possível rastrear a utilização final de todas as entradas para o processo de produção na suinocultura. Identificando a capacidade de produção de insumos e principais empresas de genéticas. Assim, o estudo verificou que a grande extensão territorial, solo fértil, técnicas produtivas e seu clima tropical favorecem efetivamente no desenvolvimento dos principais insumos da ração suína como soja e milho, responsáveis por 70 a $80 \%$ do custo total de produção do suíno vivo.

Durante a análise da cadeia produtiva, baseada nos dados da ACRISMAT (2010) e do IBGE (2012), observou-se que o Sistema Intensivo de Suínos Confinados (SISCON), é encontrado em 95\% das granjas do estado, no ano de 2010. Com relação aos tipos de granja dados apontam que $32 \%$ das granjas são do tipo CC, $17 \%$ do tipo UPL e $48 \%$ do tipo UT nas principais regiões produtoras, de suínos do estado de Mato Grosso. Outro ponto importante é que a distribuição geográfica do rebanho de suínos em MT apresentam alto índice de adensamento na região mesorregião Norte, com $72,8 \%$ do rebanho e a Sudeste, com 12,5\% do rebanho estadual.

Os dados da ACRISMAT (2010) permitiram detalhar melhor o perfil dos produtores, das granjas e dos tipos de produção do estado de Mato Grosso, evidenciando que são na maioria produtores de pequeno e médio porte sendo que $58 \%$ se originam da região sul do país (Santa Catarina, Rio Grande do Sul e Paraná) e cerca de $53 \%$ dos produtores estão na atividade há mais de 10 anos. O estudo considerou também, no segmento de abate e distribuição, os locais de destino de abate do suíno, dos principais municípios produtores do estado de MT. Cerca de $92 \%$ dos suínos 
produzidos em MT foram vendidos dentro do próprio Estado, e o município que os produtores mais apontaram como destino para abate foi o de Nova Mutum (22\%).

Mediante as informações expostas, é possível afirmar que o estudo cumpre todos seus objetivos e contribui para fornecer às instituições ligadas à cadeia produtiva da suinocultura de maneira direta ou indireta importante instrumento na tomada de decisão para possível planejamento, uma vez que detalha os insumos e etapas da produção dessa cadeia. As principais recomendações para os agentes da cadeia produtiva da suinocultura, baseadas nas observações da pesquisa são:

-Realizar pesquisas referentes ao controle dos custos do sistema produtivo, para melhor gerência dos recursos;

-Analisar detalhadamente os elos de ligação antes e depois da porteira para maior informação do recebimento e destino de insumos;

- Buscar maior poder de negociação junto a cooperativas e empresas integradoras;

Mato Grosso é mundialmente conhecido pela sua produção de grãos e pecuária, contudo a carência de informações referente ao funcionamento de suas cadeias produtivas ainda deixam a desejar. Enquanto estudos existentes na agropecuária concentram-se nos trabalhos desenvolvidos dentro da propriedade, esta pesquisa buscou incluir também os serviços gerados antes e depois da porteira, ou seja, abordar toda a cadeia produtiva da suinocultura. Portanto a originalidade deste trabalho, e as informações destinadas aos agentes da cadeia produtiva são de significativa relevância para o agronegócio do estado.

Como sugestão para estudos futuros propõe-se que seja realizada pesquisa nas cadeias produtivas de aves e bovinos, para comparações. Sugere-se ainda que esta pesquisa aborde também os custos de implantação das granjas, bem como suas instalações e maquinários.

\section{Referências}

ABCS. Associação Brasileira dos Criadores de Suínos. Um novo olhar sobre a carne suína, 2012. Disponivel em: 〈http://www.abcs.org.br/um-novo-olhar〉. Acesso em: 22 abr 2015.

ABIPECS. Associação Brasileira da Indústria Produtora e Exportadora de Carne Suína. Relatório Consumo Carne Suína 2009-2010, 2009. Disponivel em: 
<http://file.aviculturaindustrial.com.br/Material/Relatorio/abipecs_relatorio_2009_pt.p df>. Acesso em: 25 jul 2015.

Brasil pode triplicar exportações de carne suína até 2015, 2011.

Disponivel em: <http://www.abipecs.org.br/news/110/135/Brasil-pode-triplicarexportacoes-de-carne-suina-ate-2015.html>. Acesso em: 02 jan 2014.

. Exportação de carne suína por estados, 2014. Disponivel em:

$<$ http://www.abipecs.org.br/pt/estatisticas/mercado-externo/exportacoes-porestados.html>. Acesso em: 21 set 2014.

ABPA. Estatísticas da Carne Suína. Associação Brasileira de Proteína Animal, 2014. Disponivel em: <http://www.abipecs.org.br/pt/estatisticas/mundial/consumo2.html>. Acesso em: 16 out 2014.

ACRISMAT. Pesquisa com produtores e frigoríficos de Mato Grosso. Associação dos Criadores de Suínos de Mato Grosso. Cuiabá/MT. 2010.

Acrismat lançou Projeto Piloto da Inserção da Carne Suína na Merenda

Escolar em Tapurah. Associação Brasileira dos Criadores de Suínos, 2013.

Disponivel em: <http://www.abcs.org.br/component/content/article/89-noticiasdestaque-pag-inicial/1613-acrismat-lancou-projeto-piloto-da-insercao-da-carne-suinana-merenda-escolar-em-tapurah>. Acesso em: 16 jul 2015.

ALMEIDA, L. F. D. Ambiente institucional e contratos de crédito agrícola: três estudos críticos. Universidade de São Paulo. São Paulo. 2008.

ALMEIDA, M. N. D. Fatores que contribuem para falta de uniformidade de suínos de terminação. Universidade Federal de Rio Grande do Sul. Porto Alegre, p. 38. 2008.

AMARAL, L. J. D. Os aspectos legais, tributários e financeiros para as empresas do agronegócio: uma análise da empresa JBS S.A. Pontifícia Universidade Católica de Minas Gerais - Puc Minas Vírtual. Contagem. 2011.

AVERÓS. X. et al. Serum stress parameters in pigs transported to slaughter under commercial conditions in different seasons. Veterinarni Medicina. v. 52. n. 8. p. 333-342. 2007.

BATALHA, M. O.; SCARPELLI, M. Gestão do agronegócio: aspectos conceituais. In: BATALHA, M. O. Gestão do agronegócio: textos relacionados. São Carlos: EdUFScar, 2005.

BOOMEN, D. V. D. Higiene e inspeção de suínos. Universidade Castelo Branco. Botucatu, p. 96. 2008. 
BUAINAIN, Antônio Márcio; BATALHA, Mário Otávio. Cadeia produtiva da carne bovina. Ministério da Agricultura, Pecuária e Abastecimento, Secretaria de Política Agrícola, Instituto Interamericano de Cooperação para a Agricultura ;. Brasília, p. 86. 2007. (978-85-99851-20-3).

COUTO, Eloísa Xavier; HYUN, Márcia Jinyoung; IOSHIDA, Pamella Lie Konno; OLIVEIRA, Luciel Henrique de. Caracterização, descrição e análise da cadeia produtiva de frutas orgânicas no estado de São Paulo. Jovens Pesquisadores, ano 3, $\mathrm{n}^{\mathrm{o}}$ 5, 2006.Disponível em:

<http://www.mackenzie.br/dhtm/seer/index.php/jovenspesquisadores/article/viewFile/ 871/390>. Acesso em: 13 mar 2015.

CAMPOS, E. M.; FAVA, M. Planejamento e gestão estratégica para o leite em São Paulo. ${ }^{\text {a }}$. ed. São Paulo: SEBRAE, 2007. 368 p. ISBN 978-85-7376-068-2.

CASTRO, A. M. G. D. Prospecção de cadeias produtivas e gestão da informação. Transinformação - Portal de periódicos PUC - Campinas, Campinas, 2001.

CONAB. Acompanhamento da Safra Brasileira, 2009/2010. Companhia Nacional do Abastecimento, 2010. Disponivel em:

<http://www.conab.gov.br/conabweb/download/safra/3graos_09.12.pdf >. Acesso em: 06 jan 2014.

Perspectivas para a agropecuária. Companhia Nacional de Abastecimento. Brasília. 2013. (338.5).

COSTA, B. P. C. D.; ASSUMPÇÃO, M. R. P. Competitividade na exportação de açúcar. Sustentabilidade de Negócios em Ambiente Portuário, Santos/SP, 08 out 2008. 60-96.

DARTORA, V.; MORES, N.; WOLOSZYN, N. Procedimentos básicos na produção de suínos. Boletim Informativo de Pesquisa - Embrapa Suínos e Aves e Extensão - EMATER/RS, Concórdia, n. 9, jun 1997.

DIETZE, K. Pigs for prosperity. Rome: Food and Agriculture Organization of the United Nations, v. 15, 2011. ISBN 978-92-5-107068-0. Diversification booklet number 15 .

DUARTE, J. D. O.; GARCIA, J. C.; MIRANDA, R. A. D. Cultivo do Milho: Mercado e comercialização. Embrapa Milho e Sorgo. Lagoas-MG, p. 20. 2011. (1679-012).

EMBRAPA. Sistema de produção de suínos. Empresa Brasileira de Pesquisa Agropecuária, 2011. Disponivel em: <http://sistemasdeproducao.cnptia.embrapa.br/FontesHTML/Suinos/SPSuinos/index.h tml>. Acesso em: 12 abril 2011. 
FARINA, E. M. M. Q.; NUNES, R. Desempenho do agronegócio no comércio exterior e governança nos sistemas agroindustriais das carnes de suínos e das carnes bovinas. Pensa/USP. São Paulo. 2003.

FÁVERO, J. A. Produção de Suínos - Nutrição. Embrapa Suínos e Aves, 2003. Disponivel em:

$<$ http://sistemasdeproducao.cnptia.embrapa.br/FontesHTML/Suinos/SPSuinos/nutrica o.html >. Acesso em: 20 out 2014.

FRANCO, C. et al. Estruturas de governança e transações na cadeia produtiva da suinocultura de corte integrada em Mato Grosso. Relatório de pesquisa FAPEMAT. Cuiabá/MT, p. 67. 2012.

FREUDENBERGER, K. S. Rapid Rural Appraisal (RRA) and Participatory Rural Appraisal (PRA) - A Manual for CRS Field Workers and Partners. Baltimore: CRS - Catholic Relief Services, 2011. FAO-0801-G-3034-00.

IBGE. Censo Agropecuário 2006: número de cabeças de suínos. Instituto Brasileiro de Geografia e Estatística.2006. Disponivel em:

<http://www.sidra.ibge.gov.br/bda/tabela/listabl.asp?c=1225\&z=p\&o=2\&i=P>.

Acesso em: 21 abr 2013.

Matriz de Insumo-Produto Brasil 2000/2005. Instituto Brasileiro de

Geografi a e Estatística. Rio de Janeiro, p. 57. 2008. (ISSN 1415-9813).

Pesquisa Trimestral do Abate de Animais, Instituto Brasileiro de Geografia e Estatística, 2011a. Disponivel em:

$<$ http://www.sidra.ibge.gov.br/bda/tabela/listabl.asp? $\mathrm{z}=\mathrm{t} \& \mathrm{o}=1 \& \mathrm{i}=\mathrm{P} \& \mathrm{c}=1093>$. Acesso em: 15 set 2013.

Sistema IBGE de Recuperação Automática de dados - SIDRA. Instituto Brasileiro de Geografia e Estatística, 2014. Disponivel em: <http://www.sidra.ibge.gov.br/>. Acesso em: 21 set 2014.

IMEA. Conjuntura Econômica Uma visão do PIB e VBP em Mato Grosso.

Instituto Mato-grossense de Economia Agropecuária. Cuiabá. 2014.

Estimativa safra de soja. Instituto Mato-grossense de Economia Aplicada,

2014. Disponivel em:

<http://www.imea.com.br/publicacoes.php?categoria=4\&subcategoria=9>. Acesso em: 2014 out 2014.

INDEA. Estabelecimentos Registrados no SISE. Instituto de Defesa Agropecuária do Estado de Mato Grosso, 2014. Disponivel em:

$<$ http://www.indea.mt.gov.br/inspecao-sanitaria-estadual/estabelecimentossise/estabelecimentos-registrados-no-sise/131050>. Acesso em: 15 jul 2015. 
IPARDES. Análise da competitividade da cadeia agroindustrial de carne suína no Estado do Paraná. Instituto Paranaense de Desenvolvimento Econômico e Social. Curitiba, 2002. Disponivel em:

<http://www.ipardes.gov.br/webisis.docs/cadeia_agroindustrial_suina_relatorio.pdf $>$. Acesso em: 03 jan 2014.

KUMAR, K. Rapid Appraisal Methods. [S.1.]: World Bank Regional and Sectoral Studies, 1993.

LOPES, N. Desafios e oportunidades - soja e milho. Associação dos Produtores de Soja e Milho de Mato Grosso, 2013. Disponivel em:

$<\mathrm{http}$ ///www.agricultura.gov.br/arq_editor/file/camaras_tematicas/Insumos_agropecua rios/69RO/app_aprosoja.pdf >. Acesso em: 20 out 2014.

LOPES, P. F.; REIS, R. P.; YAMAGUCHI, L. C. T. Custos e escala de produção na pecuária leiteira: estudo nos principais estados produtores do Brasil. Rev. Econ. Sociol. Rural, Brasília, v. 45, n. 3, p. 567-590, 2007. ISSN 1806-9479.

LUDKE, J. V. et al. PROSUINO: versão 3.0 para windows - Sistema de formulação de ração de custo mínimo para suínos. EMBRAPA. Concórdia - SC, p. 60. 1997. (636.4085).

MANCE, Euclides André. Solidarity-Based Productive Chains. IFiL, Curitiba, 2002. Disponivel em:

<http://solidarius.com.br/mance/biblioteca/cadeiaprodutiva-en.pdf $>$. Acesso em: 29 fev 2016.

MAPA. Sistema de vigilância sanitária na zona de peste suína clássica: manual de procedimentos. Ministério da Agricultura, Pecuária e Abastecimento, 2011.

Disponivel em:

<http://www.cidasc.sc.gov.br/html/legislacao/Sanidade\%20suideos/Manual_sistema_d e_vigil\%E2ncia_sanit\%E1ria_na_zona_livre_de_PSC.pdf >. Acesso em: 03 jan 2014.

Listagem Estabelecimentos Abate Registrados no MAPA. Ministério da Agricultura, Pecuária e Abastecimento, 2011. Disponivel em: <http://200.198.43.41/novos_informativos/gda/2011/arquivos/ListagemEstabeleciment osAbateRegistrados_MAPA.pdf>. Acesso em: 24 out 2014.

Manual do Sistema Nacional de Informação Zoossanitária. Ministério da Agricultura, Pecuária e Abastecimento. Brasília, p. 40. 2013.

MARION, J. C. Contabilidade rural. 11 a . ed. São Paulo: Atlas, 2010. 251 p. MEINCKE, W. A importância da fase de terminação no sistema de produção de suínos. Suino.com, 2010. Disponivel em:

<http://www.suino.com.br/GeneticaNoticia.aspx?codigoNot=RSY4DBXUxbE=\&title $=\mathrm{A}+\mathrm{IMPORTANCIA}+\mathrm{DA}+\mathrm{FASE}+\mathrm{DE}+\mathrm{TERMINACAO}+\mathrm{NO}+\mathrm{SISTEMA}+\mathrm{DE}+\mathrm{PRO}$ DUCAO+DE+SUINOS.+-+POR+WERNER+MEINCKE>. Acesso em: 23 out 2014. 
MELZ, L. J. Competitividade da cadeia produtiva de carne de frango em mato grosso: avaliação dos segmentos de avicultura e processamento. [Dissertação de mestrado] Engenharia de Produção. Universidade Federal de São Carlos. São Carlos: UFSCar. 2010.

MELZ, L. J. et al. Estudo sobre a competitividade da avicultura e processamento de carne de frango em Mato Grosso. Cáceres: UNEMAT, 2012. 187 p. ISBN 97885-7911-068-9.

MENEGUETTI, G. A. Dinâmica e espaços de mercado na cadeia de suínos - da produção independente aos contratos de integração - as pequenas indústrias formais e informais como estratégia de inserção nos mercados. [Dissertação de mestrado] Mestrado em Desenvolvimento, Agricultura e Sociedade. Rio de Janeiro: Universidade Federal Rural do Rio de Janeiro. 2000.

MENEZES, C. A. M. D. Contabilidade Tributária I. Faculdade da Cidade de Salvador. Salvador. 2007.

MIELE, M. Consumo de carne suína no Brasil: indicadores, evolução e diferenças regionais. Suinocultura Industrial. Suinocultura Industrial: São Paulo, ano 33, n. 2, n. 239, p. 14-23, 2011.

MIELE, M.; WAQUIL, P. D. Cadeia produtiva da carne suína no Brasil, Brasília: Revista de Política Agrícola, v. 16, p. 75-87, 2007a.

Estrutura e dinâmica dos contratos na suinocultura de Santa Catarina: um estudo de casos múltiplos, São Paulo: Revista de Estudos Econômicos, v. 37, p. 817-847, 2007b.

MILLER, R. E.; BLAIR, P. D. Input-Output Analysis: Foundations and Extensions. 2a . ed. Cambridge: Cambridge University Press, 2009.

MONTIGAUD, J. C. Lês filières fruits et legumes et la grande distribution: méthodes d'analyse et resultats. Montpellier. Centre Internacional de Hautes Études Agronomiques Mediterraneennes (CIHEAM): Institut Agronomique Mediterraneen de Montpellier, 1991.

NASCIMENTO, L. J. Rússia libera exportações de quase 100 frigoríficos brasileiros. G1 Mato Grosso, 2014. Disponivel em: <http://g1.globo.com/matogrosso/agrodebate/noticia/2014/08/russia-libera-exportacoes-de-quase-100frigorificos-brasileiros.html>. Acesso em: 16 jul 2015.

NEVES, M. F. Planejamento e Gestão Estratégica de Marketing para Associações, Organizações Setoriais ou para Cadeias Produtivas. In: ZYLBERSZTAJN, D.; NEVES, E. M.; NEVES, M. F. Agronegócio do Brasil. São Paulo: Saraiva, 2005. NORTH, D. Custos de transação, instituições e desempenho econômico. Rio de Janeiro: Instituto Liberal, 1994. 
NORTH, D. C. Institutions, institutional change, and economic performance. Cambridge University Press. Cambridge. 1990.

NICOLAIEWSKY, S. et al. Suinocultura Intensiva. $1^{\text {a }}$. ed. Concórdia: Embrapa, 1998. 388 p. ISBN 85-7383-036-0.

PACHECO, J. W. Guia técnico ambiental de frigoríficos - industrialização de carnes (bovina e suína). CETESB - Biblioteca. São Paulo, p. 85. 2006. (121251 : 878740).

PATTANAYAK, S. K. Rapid Appraisal Methods, North Carolina State University, 2004. Disponivel em:

<http://www.ncsu.edu/project/cnrint/GHANA/rra_notebook.pdf >. Acesso em: 17 nov 2014.

PEREIRA, T. L. Fluxo pré-abate de suínos no Estado de Mato Grosso e efeito da densidade no transporte e da classe sexual sobre o bem estar e a qualidade de carne. [Tese de Doutorado].Universidade Federal de Mato Grosso Sinop, p. 98. 2014. (P436f).

PEREIRA, T. L.; CORASSA, A. Fluxo do transporte de suínos para abate no Estado de Mato Grosso. Revista Brasileira de Saúde Produção Animal, Salvador, v. 15, n. 04, p. 970-982, out/dez 2014. ISSN 15199940.

PIRES, S. R. I. Gestão da Cadeia de Suprimentos (Supply Chain Management): Conceitos, estratégias práticas e casos. $2^{a}$. ed. São Paulo: Atlas S.A., 2009. ISBN 978-85-224-5304-7.

ROCHA, D. T. Competitividade entre os sistemas integrado e independente de produção de suínos. [Dissertação de mestrado] Mestrado em Economia. Programa de Pós-Graduação em Economia Aplicada. Universidade Federal de Viçosa. Viçosa/MG. 2006.

ROCHA, D. T. D. et al. Análise de risco de sistemas de produção de suínos, integrado e independente, em períodos de alta e baixa rentabilidade. XLV Congresso da SOBER, Londrina, p. 17, 2007.

ROQUE, Andreia. Estudo preliminar da cadeia produtiva: turismo rural Brasil. Instituto Interamericano de Cooperação para a Agricultura- IICA Brasil. Brasilia, 2013.

SANTINI, G. A.; SOUZA FILHO, H. M. Mudanças tecnológicas em cadeias agroindustriais: uma análise dos elos de processamento da pecuária de corte, avicultura de corte e suinocultura, In: Congresso da Sociedade Brasileira de Economia Rural, Cuiabá/MT, v. 42, p. 1-12, 2004 a. 
SARAIVA, M. B. Índice de desempenho competitivo da suinocultura das principais regiões produtoras de Mato Grosso: Análise e fatores determinantes. [Dissertação de mestrado]. Cuiabá: Universidade Federal de Mato Grosso. 2012.

SEBRAE. Informações de Mercado sobre suinocultura (carne "in natura", embutidos e defumados). Serviço Brasileiro de Apoio às Micro e Pequenas Empresas. São Paulo, p. 94. 2008.

SILVA FILHA, O. L. et al. Caracterização da criação de suínos locais em sistema de utilização tradicional no estado da Paraíba. Archivos de Zootecnia, v. 54, , 2005. 523-528.

STAATZ, J. M. Notes on the use of subsector analysis as a diagnostic tool for linking industry and agiculture. Michigan State University: Department of Agricultural Economics. Staff Paper 97-4. Michigan. 1997.

SÜPTITZ, L. A. S.; WOBERTO, M. C. R.; HOFER, E. Gestão de custos na suinocultura: um estudo de caso. Custos e @ gronegócio on line, Curitiba, v. 5, n. 1, p. 2-21, jan/abr 2009. ISSN 1808-2882.

USAID. USING RAPID APPRAISAL METHODS. $2^{\text {a }}$. ed. [S.1.]: United States Agency International Development, v. 5, 2010.

WEYDMANN, C. L. et al. Cadeia produtiva suinícola, 2005. Disponivel em: <http://novosite.fepese.org.br/portaldeeconomiasc/arquivos/links/alimentos_agronegocio/2005\%20Cadeia\%20Suinos\%20master\%20p lan\%20SC.pdf>. Acesso em: 10 jun 2013.

ZARDO, A. O.; LIMA, G. J. M. M. Alimentos para suínos. Embrapa Suínos e Aves e EMATER/RS. Concórdia/SC, p. 60. 1999.

Submetido em: 18/03/16

Aceito em: 01/06/16 